\title{
ANÁLISE ESTÁTICA DA CONSTRUÇÃO HISTÓRICA LUSO-BRASILEIRA DO SÉCULO XIX
}

\author{
ISAAC D. PEREIRA, PEDRO \\ Estudante \\ LAREB - UFC, Campus Russas \\ Ceará; Brasil \\ isaacufcrussas@gmail.com
}

\author{
MINEIRO A. NETO, FRANCISCO \\ Estudante \\ LAREB - UFC, Campus Russas \\ Ceará; Brasil \\ mineironeto1@gmail.com
}

\author{
FREIRES PINTO, MARCELO \\ Estudante \\ LAREB - UFC, Campus Russas \\ Ceará; Brasil \\ marcelofreires18@gmail.com
}

\author{
NILTON L. SOUSA, ISRAEL \\ Estudante \\ LAREB - UFC, Campus Russas \\ Ceará; Brasil \\ israelnlsousa@gmail.com
}

\author{
FERNANDES T. MESQUITA, ESEQUIEL \\ Professor, $\mathrm{PhD}$. \\ LAREB - UFC, Campus Russas \\ Ceará; Brasil \\ emesquita@ufc.br
}

\section{RESUMO}

Os patrimônios históricos são instrumentos que preservam a memoria e possuem um alto valor cultural. Com base nessa relevância e os metodos construtivos utilizados na época, faz-se inescusável a sua conservação. Nesta circunstância, o conjunto histórico erguido na cidade de Quixadá, localizado no Estado do Ceará, distante $169 \mathrm{~km}$ da capital, Fortaleza, foi a primeira obra hidraulica moderna do Brasil. Os patrimônios analisados serviram de auxílio para a confecção da Barragem Cedro, durante os anos de 1884 a 1906. Com o passar dos anos as edificações sofreram com o ambiente invasivo e ações antrópicas, e suas estruturas foram fragilizadas. Nesse sentido, o presente trabalho busca analisar o comportamento estático da edificação com a utilização de um modelo numéricos que considera infomações obtidas em levantamentos geométricos e foi obtido por meio do software ANSYS®, versão 17.1, cujas ferramentas possibilitaram confeccionar a malha e realizar simulações. Os resultados obtidos fazem uso das variáveis Deslocamentos Direcionais, Deslocamentos Totais e Tensões Principais, de modo a identificar as zonas de concentrações de tensões e deformações. Ademais, o trabalho contribuiu para uma melhor compreensão dos mecanismos de danos atuantes na edificação, bem como, formenta investigações em prol da preservação de bens materiais que compõem o patrimônio histórico.

Palavras-chave: Analise estática, Patrimônio histórico, Barragem Cedro.

\begin{abstract}
Historical heritage is an instrument that preserves memory and has a high cultural value. Based on this relevance and the construction methods used at the time, its conservation is inexcusable. In this circumstance, the historic complex built in the city of Quixadá, located in the State of Ceará, $169 \mathrm{~km}$ from the capital, Fortaleza, was the first modern hydraulic work in Brazil. The analyzed assets served as an aid for the construction of the Cedro Dam, during the years 1884 to 1906 . Over the years, the buildings suffered from the invasive environment and anthropic actions, and their structures were weakened. In this sense, the present work seeks to analyze the static behavior of the building with the use of a numerical model that considers information obtained in geometric surveys and was obtained using the software ANSYS $®$, version 17.1, whose tools made it possible to make the mesh and perform simulations. The results obtained make use of the variables Directional Displacements, Total Displacements and Principal Stresses, in order to identify the zones of stress concentrations and deformations. In addition, the work contributed to a better understanding of the damage mechanisms at work in the building, as well as forging investigations in favor of the preservation of material goods that make up the historical heritage.
\end{abstract}

Keywords: Statistical analysis, Historical Heritage, Cedro Dam.

\section{INTRODUÇÃ̃O}

As edificações históricas de uma sociedade possuem grande relevância cultural, pois testemunham a história e prosperidade de um povo. Vista tal importância, faz-se necessário firmar ações de conhecimento do patrimônio histórico. Assim, pode-se ressaltar a importância de órgãos como Instituto do Patrimônio Histórico e Artístico Nacional 
(IPHAN), a nível nacional, e do Conselho Internacional de Monumentos e Sítios (ICOMOS), a nível internacional, ambos desempenham papel importante na afirmação e preservação dos patrimônios históricos, além de regularem processos de reconhecimento e tombamentos.

No que tange às construções históricas, segundo Mesquita (2017), devido ao seu elevado valor cultural, variabilidade e complexidade dos sistemas estruturais, utilizados nestas construções, estas estabelecem um campo desafiador para a promoção de novas técnicas de caracterização, avaliação e reabilitação estrutural. Ademais, analisar as estruturas históricas ainda é um desafio na engenharia devido a alta complexidade geométrica e a falta de conhecimento dos materias utilizados, considerando também suas modificações durante o tempo e o desgaste do material. (SANTOS et al., 2016). Em consonância com ICOMOS (2001), a análise estrutural é uma ferramenta imprescindível, dado que um modelo calibrado adequadamente permite comparar os danos gerados e os fenomenos associados a sua complexidade, possibilitando assim a indicar o fluxo das tensões e suas possíveis áreas críticas.

Nessa conjuntura, a cidade de Quixadá, localizada na região Nordeste do Estado do Ceará, possui a primeira grande obra direcionada para o combate da seca do país, o conjunto de barragens no entorno do Açude Cedro. Construída durante o Governo Imperial, após o efeito negativo da grande seca entre os anos 1877 e 1879, buscava reduzir os processos migratórios para as grandes cidades e promover naquela região antes inóspita, uma condição de sobrevivência desenvolvimento socioecônomico e a possibilidade de povoamento em regiões inóspitas.

Como forma de contribuição ao meio tecnocientífico, o presente trabalho busca analisar e caracterizar o comportamento estático do galpão de máquinas da Barragem do Cedro, com à utilização de um modelo baseado em Metódo dos Elementos Finitos (MEF), de modo a compreender como a estrutura reage frente as cargas e identificar possíveis zonas vulneráveis, anunciadas por concentrações de tensões e deformações excessivas, ambas variáveis quantificadas durante simulações sob as modalidades de Deslocamentos Direcionais, Deslocamentos Totais e Tensões Equivalentes. Além disso, o estudo busca corroborar para o desenvolvimento na área de Engenharia de Patrimônio sob a perspectiva de conservação dos patrimônios históricos.

\section{ESTUDO DE CASO}

\subsection{Características históricas e construtivas dos galpões de máquinas da Barragem do Cedro}

Localizado na cidade de Quixadá, no estado do Ceará, e tombado como patrimônio histórico cultural em 1977 pelo IPHAN, os galpões da Barragem do Cedro, formam em conjunto com a barragem e a vila operário um complexo patrimonial, construídos e projetados entre o século XIX e XX.

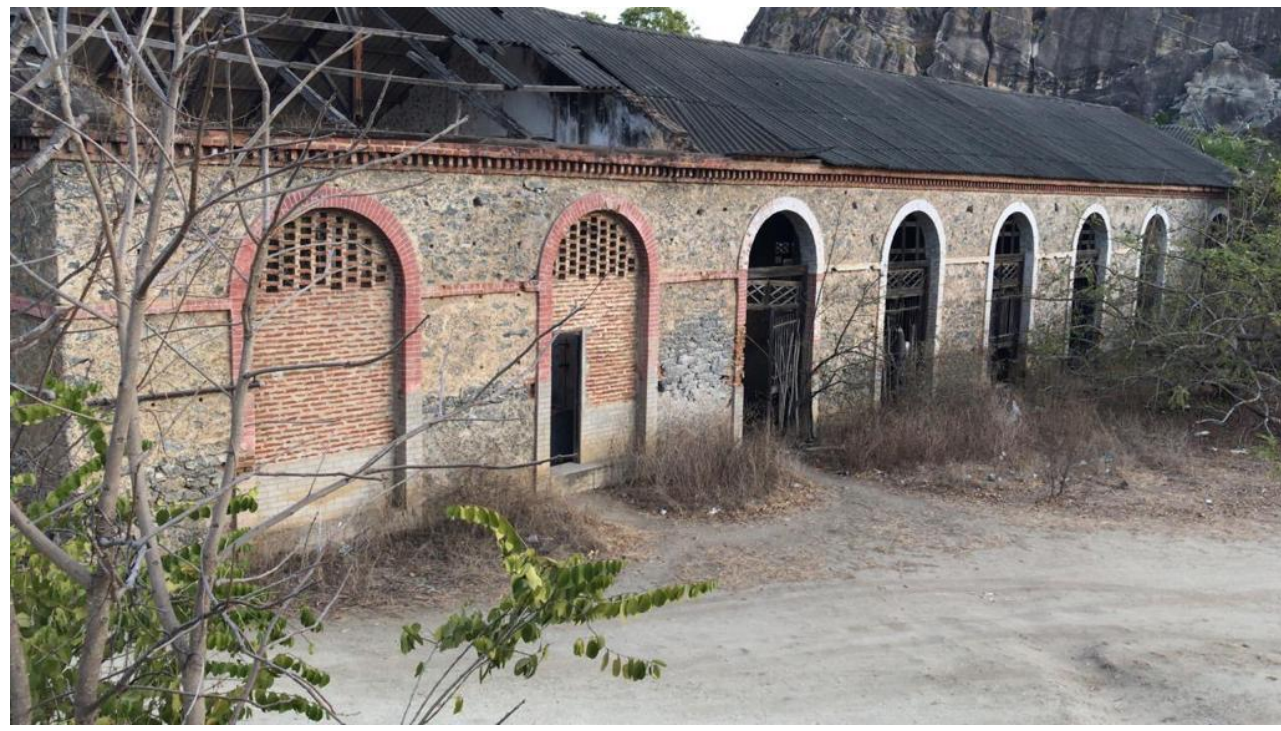

Figura 1: Galpão de máquinas da Barragem do Cedro (Vista Externa) 
O monumento histórico possui uma estrutura mista, feita em cantaria, tratando-se de método construtivo predominante no seculo XIX, com aplicabilidade atrelada a existência de uma bacia local de sienito, possibilitando assim uma exploração local e sua utilização para a concepção dos galpões e a fabricação da Barragem do Cedro. E para a construções das aberturas, que são em formatos de arco preferiu-se a utilização de tijolos cerâmicos. Ademais, a arquitetura dos galpões é bastante simétrica, possui a mesma quantidade de aberturas laterias, ambas com a mesma caractericas circular. Por fim, a cobertura é compostas por telha cerâmica, rufos e a tesoura como elemento de sustentação. A seguir pode ser verificado a estrutura interna do galpão central com base na Figura2.

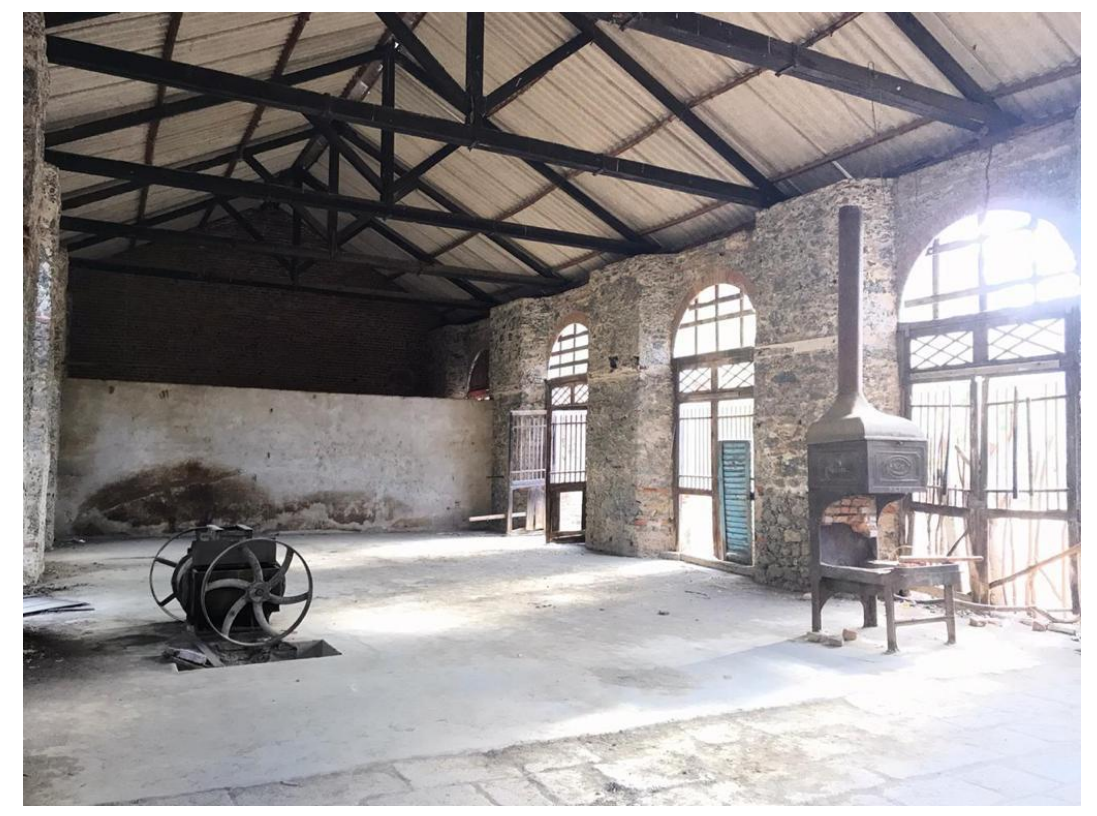

Figura 2: Galpão de máquinas da Barragem do Cedro (Vista Interna)

Os galpões possuem uma área total de aproximadamente $300 \mathrm{~m}^{2}, 7$ portas em ambas laterais da edificação histórica e duas portas internas que interligam os galpões. Além disso, existem 3 galpões e as espessuras das paredes externas variam de $60 \mathrm{~cm}$ a $100 \mathrm{~cm}$, ao passo que as paredes internas possuem aproximadamente $30 \mathrm{~cm}$. A seguir podemos analisar com base na Figura 3 a representação da geometria do galpão com base no levantamento geométrico realizado.

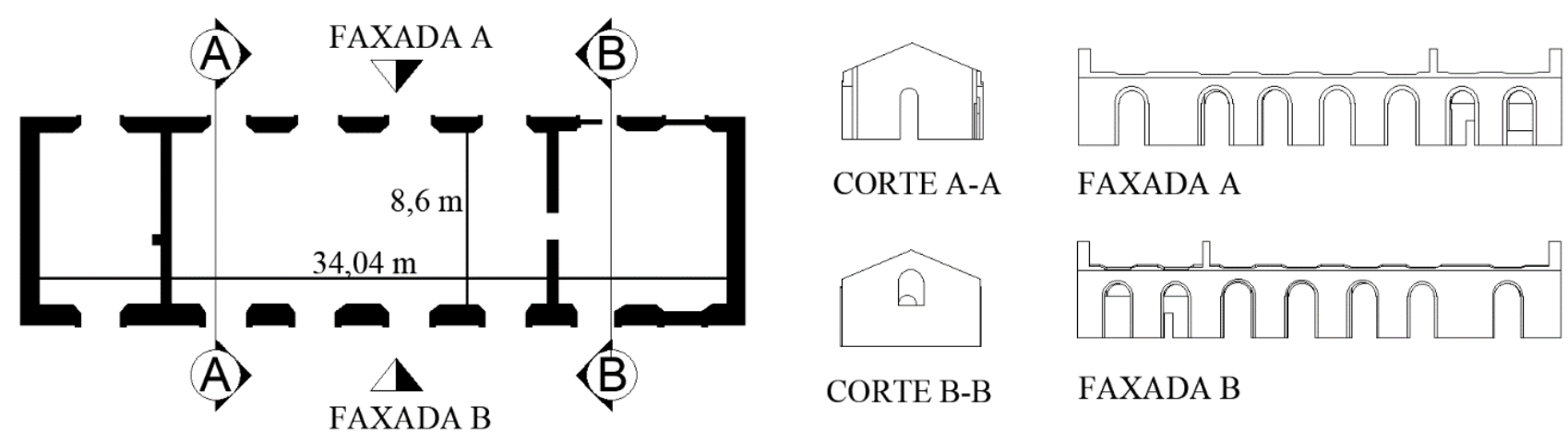

Figura 3: Representação do levantamento geométrico dos Galpões

No que tange o estado atual de conservação da estrutura, apresenta-se em mal estado de conservação, possuindo vegetação enraizada, fissuras, perdas de esquadrias, desagregação de revestimento entre a alvenaria e cobertura danificada. Vale salientar que desde sua construção a edificação jamais passou por processos manutenção, e com isso os mecanismos de degradação causaram tais danos.

\subsection{Modelagem numérica}


No presente artigo foi analisada uma estrutura de alveria de pedra e tijolos ceramicos maciços, que apresentam propriedades mecânicas distintas. É sabido que a modelagem de estruturas históricas é um desafio para engenharia de estruturas devido a grande variedade de materias e técnicas construtivas utilizadas, tornando assim a sua modelagem uma tarefa de elevada complexidade.

Para esse fim foi construído um modelo tridimensional de elementos finitos, tendo em vista uma macromodelagem, aproximando as alvenarias de um material isotrópico, para análise em no regime elástico. Optou-se pela técnica de macromodelagem, pois a mesma recorre à representação das partes inteiras da estrutura com paredes ou vigas (macroelementos) de comportamento linear e para cada macroelemento haverá um lei constitutiva estabelecidas em termos de forças e deformações generalizadas, possibilitando assim um comportamento do material mais próximo da realidade, portanto, com maior nível de confiabilidade. (NUNES R. F, 2013)

Devido à falta de plantas baixas originais dos galpões, foram realizadas medições durante a inspeção in loco para a caracterização geométrica da estrutura. Com base no levantamento geométrico foi possivel realizar a confecção do modelo em 3D no software $C A D$, que a posteriori foi otimizado e importado para o software Ansys® (versão 17.1) em formato sat., onde foi discretizado utilizando-se uma malha de elementos finitos. Buscou-se um modelo numérico o mais próximo possivel da realidade, porém algumas simplificações foram realizadas em busca de minimizar a ocorrência de problemas de discretização. Para isso, optou-se pela utilização do elemento SOLID187, tendo em vista que os elementos argamassados e os elementos cerâmicos foram aproximados para um material homogêneo, com base na precisão requerida para a análise. O elemento é um elemento tetraédrico de 10 nós com 3 graus de liberdade em cada nó. Com isso obtiveram-se 67330 elementos e 120095 nós. A figura 5 mostra o modelo 3D concebido para a edificação histórica.

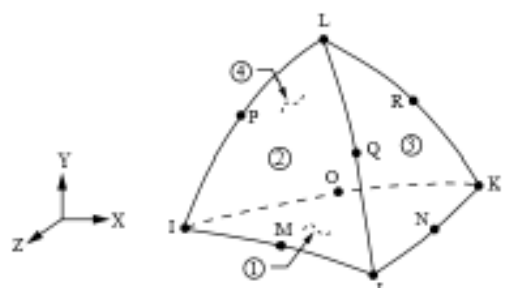

Figura 4: Elemento SOLID 187. Fonte: Biblioteca ANSYS 17.1
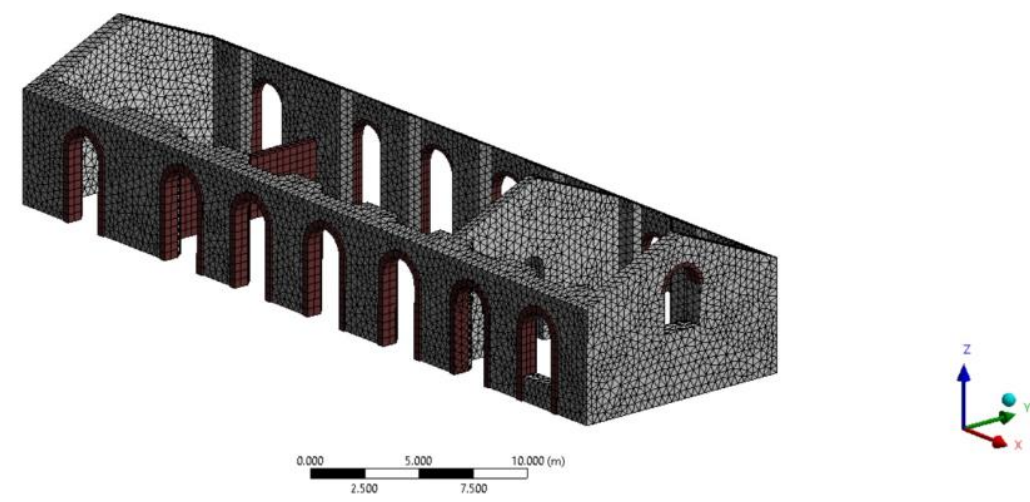

Figura 5: Modelo numérico em elementos finitos 3D dos galpões históricos da Barragem Cedro

\subsection{Carregamentos e propriedades mecânicas da alvenaria do modelo}

Para a determinação das solicitações atuantes na modelo, recorreu-se a literatura, tendo em vista a inviabilidade de realizar de ensaios experimentais que possibilitem obter com maior efetividade as propriedades mecânicas das alvenarias da edificação. Com base nisso, o Módulo de Elasticidade (E) para a alvenaria de pedra e alvenaria cerâmica foi obtida a partir do regulamento italiano "Norme Tecniche per le costruzioni” do ano de 2018 (MIT, 2018) também se levou em consideração também as determinações NCT (MIT, 2018) e Brandão (2017). Já o Peso Específico (w) e a Resistência à compressão (fc) foram obtidos também com base no regulamento italiano do ano de 2018 (MIT,2018). A 
resistência a tração (ft) foi obtida com base no trabalho de Brandão (2017). E por último, o coeficiente de Poisson foi obtido com base nos trabalhos de Branco (2007), Frazão (2013) e Brandão (2017). A tabela 1 abaixo resume as propriedades mecânicas utilizadas para a confecção do modelo numérico dos galpões.

\begin{tabular}{|c|c|c|}
\hline \multirow{2}{*}{$\begin{array}{l}\text { Propriedade } \\
\text { Mecânica }\end{array}$} & \multicolumn{2}{|c|}{ Magnitude } \\
\hline & $\begin{array}{l}\text { Alvenaria de } \\
\text { Pedra }\end{array}$ & $\begin{array}{l}\text { Alvenaria } \\
\text { Cerâmica }\end{array}$ \\
\hline E (Gpa). & 4,75 & 1,7 \\
\hline $\mathrm{w}\left(\mathrm{kN} / \mathrm{m}^{3}\right)$ & 22 & 18 \\
\hline fc (Mpa) & 4,75 & 3,2 \\
\hline ft (Mpa) & 0,24 & 0,16 \\
\hline $\mathrm{v}$ & 0,2 & 0,2 \\
\hline
\end{tabular}

Para a cobertura, os esforços foram quantificados com base nos trabalhos de Neves (2008), que correspondeu a 1,30 $\mathrm{kN} / \mathrm{m}^{2}$, o qual já considera todos os elementos da cobertura (ripas, telhas, caibros e treliças). Com base na NBR 6120 (ABNT, 1980), é indicada uma cara acidental de $0,50 \mathrm{kN} / \mathrm{m}^{2}$. Somando-se estas duas cargas, o resultado foi de 1,80 $\mathrm{kN} / \mathrm{m}^{2}$. Ainda, Brandão (2017), indica uma majoração de $50 \%$ no montante da carga total do telhado $\left(1,80 \mathrm{kN} / \mathrm{m}^{2}\right)$. Portanto, o carregamento total da coberta é de $1,80 \mathrm{kN} / \mathrm{m}^{2}$ mais $0,90 \mathrm{kN} / \mathrm{m}^{2}$, que resulta em 2,70 kN/m2.

\section{RESULTADOS E DISCUSSÕES}

\subsection{Deslocamentos direcionais}

Com base nas caracterizações dos carregamentos e propriedades mecânicas definidas anteriormente, com elaboração do modelo numérico foi possível realizar as simulações. Desse modo, obteve-se os deslocamentos direcionais nos eixos X, Y e Z, dirigido da seguinte forma:

- o eixo X está relacionado ao sentido longitudinal horizontal dos galpões;

- $\quad$ o eixo Y no sentido vertical;

- $\quad$ e o eixo $\mathrm{Z}$ no sentido transversal dos galpões.

O eixo X, apresenta deslocamentos de maior amplitude, aproximadamente $0,051 \mathrm{~mm}$ no sentido positivo do eixo, localizado na fachada frontal, acima da abertura circular, a medida que o eixo negativo do atingiram valores com magnitude de $0,042 \mathrm{~mm}$, com ênfase na alvenaria que separa o galpão central do galpão 2 (Figura 6). O deslocamento máximo na região dos arcos deve está ligado ao fato dessa região ser propícia ao acumulo de tensões provenientes das reorientações dos esforços atuantes.
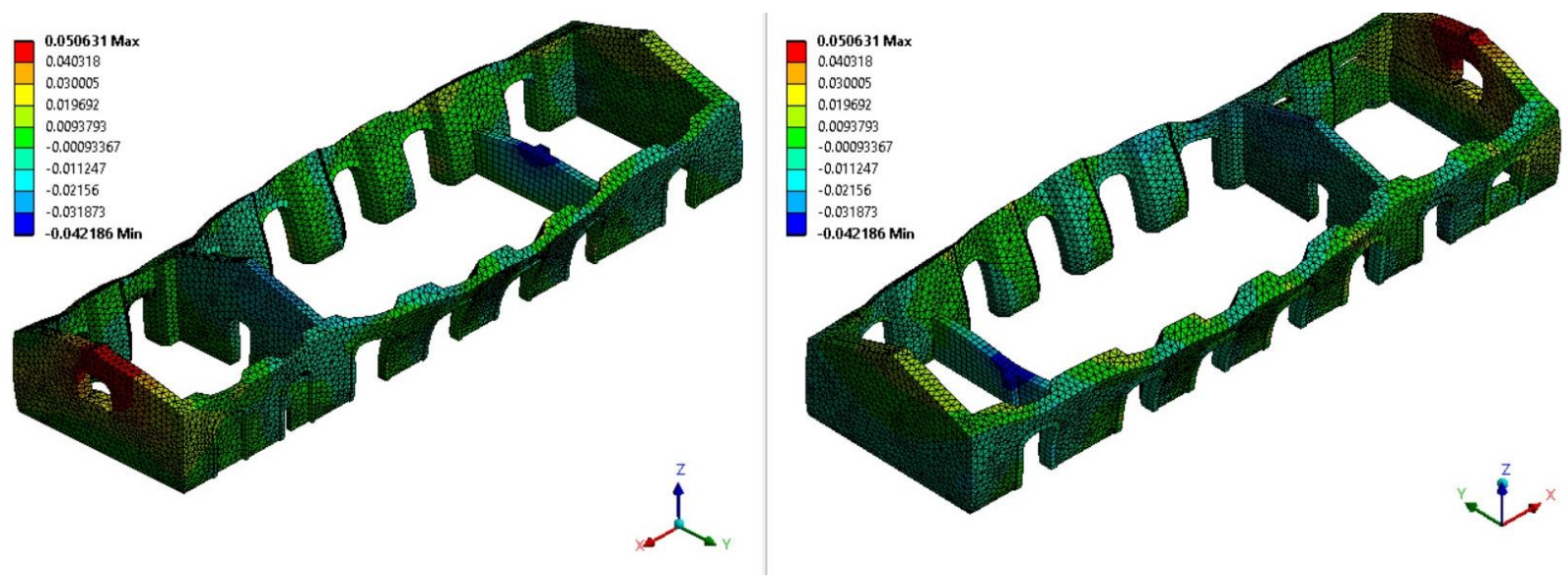

Figura 6: Deslocamentos direcionais em X. Unidade em milímetros. 
Analogamente, o eixo Y expressou deslocamento com dimensões máxima no eixo positivo, com magnitude de aproximadamente $0,22 \mathrm{~mm}$, ao passo que o sentido negativo, obteve-se valores de amplitude máxima de aproximadamento $0,18 \mathrm{~mm}$. Pode-se analisar que os deslocamentos máximos estão localizados no centro das alvenarias laterais do galpão, isso pode esta relacionado com a esbeltez dessas alvenarias, tendo em vista um elevado vão e a presença das aberturas que reduz mais ainda a rigidez das alvenarias, ocasionando uma concentração de esforços em ambas as laterais.
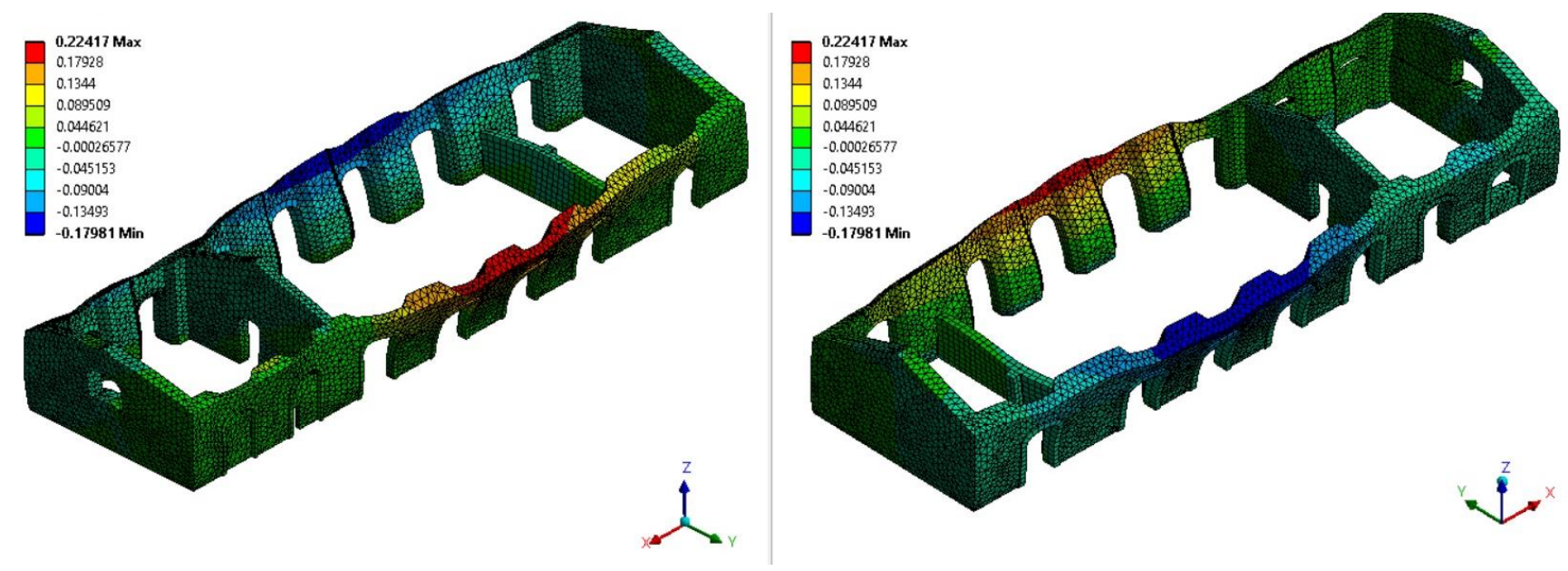

Figura 7: Deslocamentos direcionais em Y. Unidade em milímetros.

Por último, no eixo $\mathrm{Z}$ é possível analisar com base na modelagem numérica dos galpões de máquinas da Barragem Cedro, que os deslocamentos apresentadas no eixo positivo possuem magnitude nula, enquanto o eixo negativo manifestou magnitude de até $0,18 \mathrm{~mm}$. O deslocamentos máximo se localiza no topo das aberturas circulares e nas duas cumeeiras. Isso deve-se ao carregamento proveniente do telhado e o peso próprio da estrutura. Já os deslocamentos que apresentam valores nulos, localizam-se na base do edifício histórico, e possuem justificativa atrelada as condições de engastamento impostas nas fundações, possibilitando uma maior rigidez e menores deslocamentos.
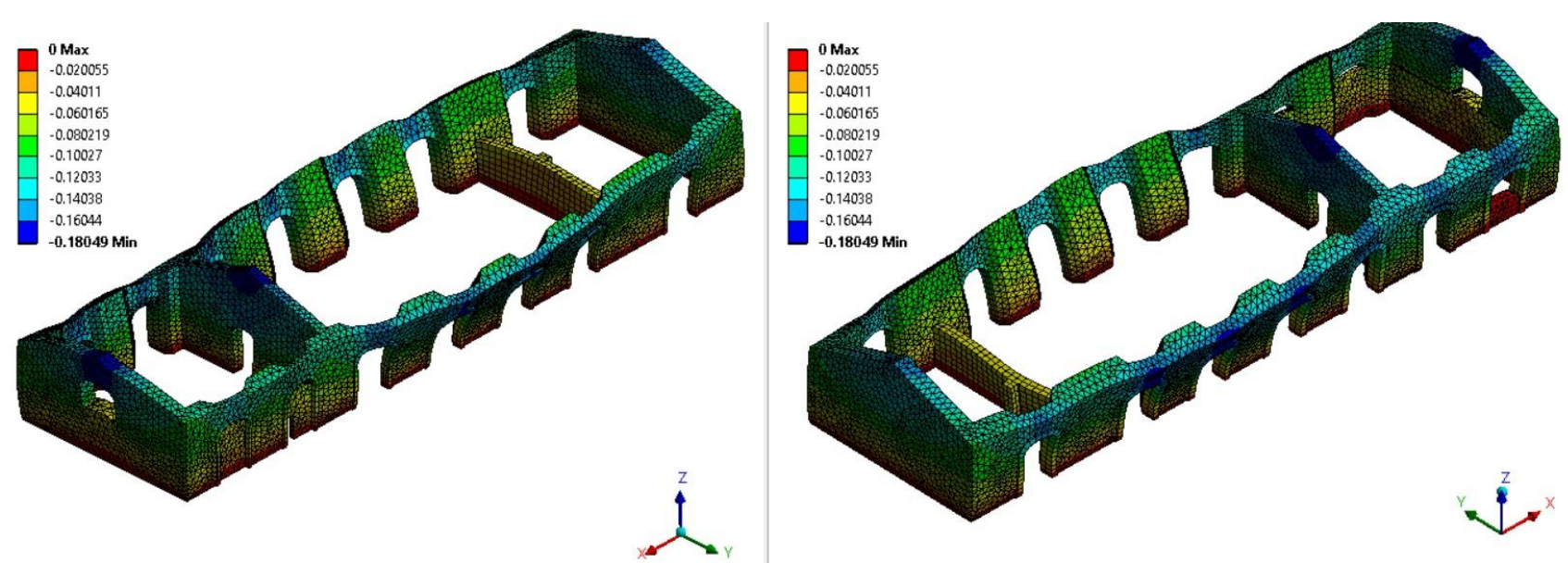

Figura 8: Deslocamentos direcionais em Z. Unidade em milímetros.

\subsection{Deslocamentos Totais}

Com o curso das simulações mostrou-se importante analisar o comportamento da edificação histórica no que tange Os deslocamentos totais. Nesta perspectiva nota-se um valor máximo de aproximadamente 0,26 mm. Esse fato ocorre 
devido a geometria apresentada, tendo em vista uma maior esbeltez nos elementos que compõem a região, promovendo redução da sua rigidez, tornando-a o local de maior solicitação global.
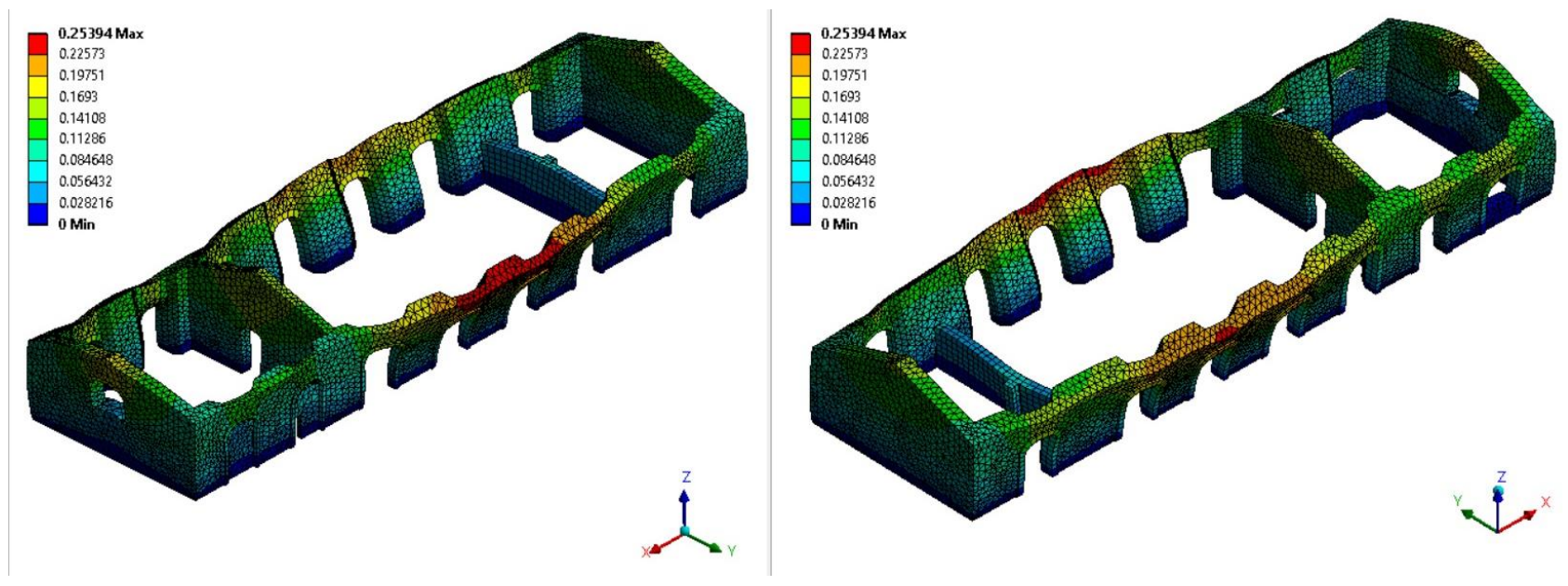

Figura 9: Deslocamentos Totais. Unidade em milímetros.

\subsection{Tensões Principais}

Com base nas simulações, foi possível notar a existência de tensões provenientes de esforços de tração, representadas na Figura 10. Analisando a estrutura de maneira global, é factível notar que os valores máximos de tração estão localizados na abertura circular da fachada frontal e na alvenaria que divide o galpão principal. Porém, os esforços se mostram ínfimes, tendo em vista que os valores são próximos de zero. Portanto, a alvenaria do modelo foi concebida uma tensão máxima de tração de $0,16 \mathrm{MPa}$, tornando possível concluir que com base nas simplificações adotadas, que o modelo apresenta resistência aos esforços de tração.
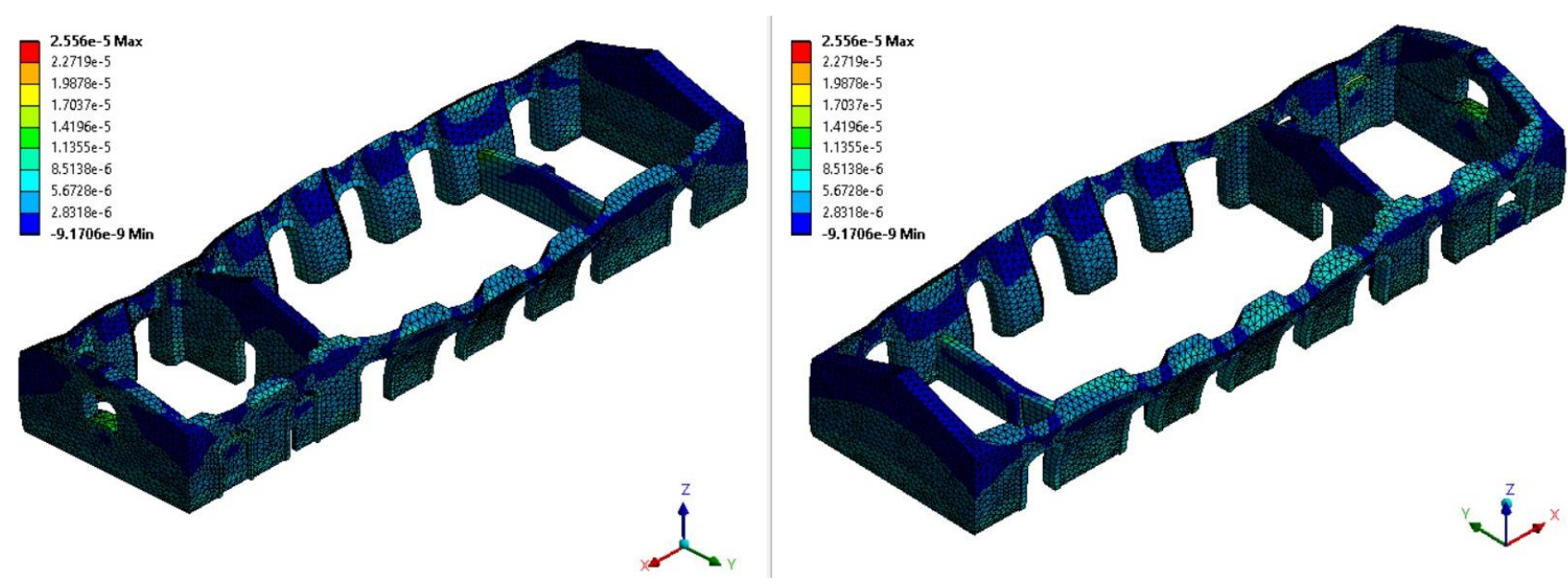

Figura 10: Tensão Principal de Tração. Unidade em MPa.

$\mathrm{Na}$ figura 11, são expostos os resultados da modelagem com relação as simulações das tensões principais de compressão atuante em toda a edificação. Nota-se que as amplitudes atingem aproximadamente $0,35 \mathrm{MPa}$, um valor inferior ao de 3,2 MPa conferido ao modelo. É possível localizar, com base na figura 10, que os esforços encontram-se na região inferior das alvenarias, próximo ao nível do terreno. 

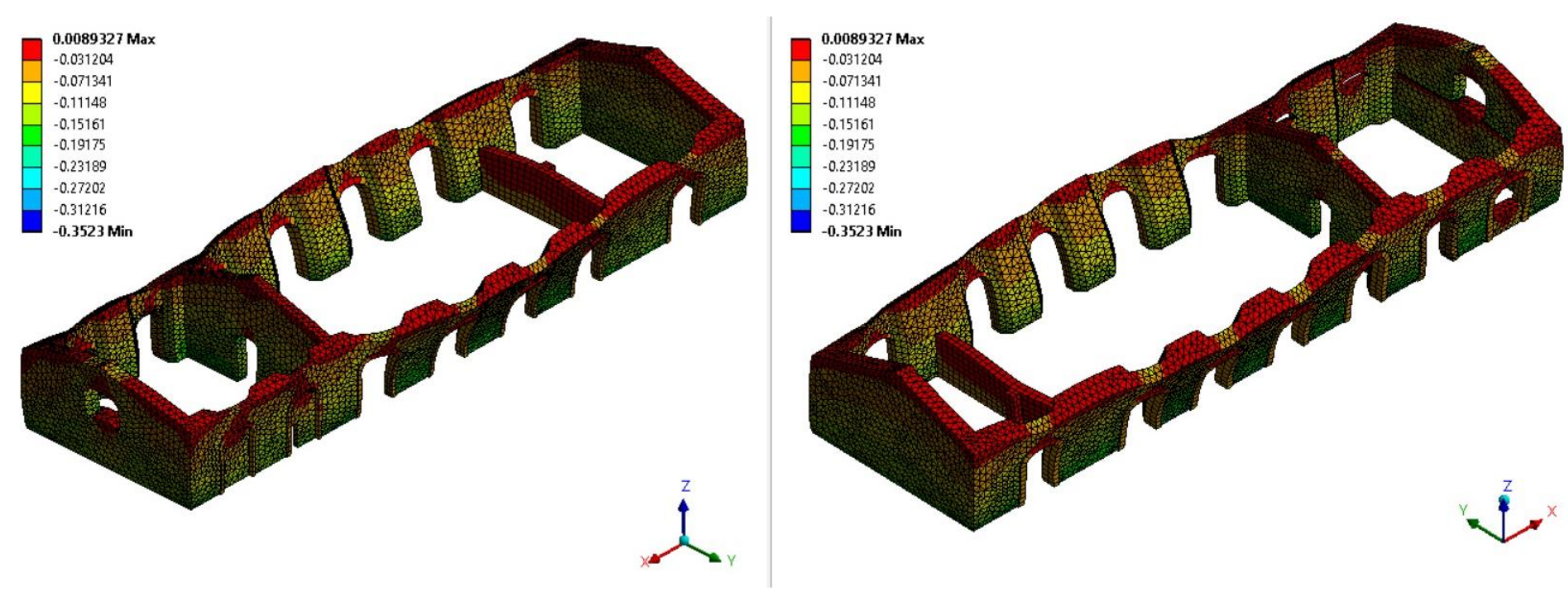

Figura 11: Tensão Principal de Compressão. Unidade em MPa.

\section{CONCLUSÕES}

Os galpões de máquinas da barragem do Cedro é uma edificação que compõe o patrimônio histórico, edificado no século XIX, devido à construção da barragem, que possibilitou aos nativos o desenvolvimento da pecuária e agricultura local, transformando a economia e reduzindo os processos migratórios. Contudo, mostra-se a extrema importância cultural e social das estruturas, pois estão atreladas a um momento marcante na história nacional. Devido a isto, mostrou-se interessante a realização de análises estruturais de modo a investigar as condições físicas da edificação e assim auxiliar na sua preservação. Nesse sentido, optou-se por analisar o comportamento estrutural da construção histórica por meio do MEF, buscando identificar mecanismos danosos sob as variáveis de tensões e deslocamentos, e possíveis regiões suscetíveis a danos.

No geral é possível concluir que a estrutura possui um comportamento satisfatório, tendo em vista que as tensões de tração e compressão são inferiores aos valores máximos atribuídos ao modelo. Quanto as deformações globais da estrutura, concentram-se na região central das fachadas laterais, não apresentam módulos significativos para causar danos. A estrutura composta por alvenaria cerâmica e alvenaria de pedra, manifestando respostas satisfatórias frente as solicitações impostas.

Vale salientar a importância das simulações computacionais, como uma ferramenta de grande potencial para auxiliar em diagnósticos que necessitam de diversos parâmetros para tomadas de decisões. No caso das edificações históricas, permitiram uma análise com resultados que consideraram parâmetros de elevada complexidade, promovendo significativas informações técnicas a respeito do comportamento estrutural e a prevenção de danos.

Em síntese, as metodologias presentes no estudo contribuem para a manutenção da seguridade e funcionamento conforme as exigências de desempenho, passíveis de aplicabilidade em construções históricas como os galpões da Barragem do Cedro, como também, estimular atividades dessa natureza e contribuir para o desenvolvimento tecno científico na área de Engenharia do Patrimônio.

\section{REFERÊNCIAS}

ASSOCIAÇÃO BRASILEIRA DE NORMAS TÉCNICAS. NBR 6120: Cargas para o cálculo de estruturas de edificações. Rio de Janeiro, 1980.

BRANCO, M. E. M. Reforço Sísmico de Edifícios de Alvenaria -Aplicação a edifícios "Gaioleiros". 2007. 98 f. Dissertação (Mestrado em Engenharia Civil) -Instituto Superior Técnico, Lisboa, 2007. 
BRANDÃO, F. Análise do Comportamento Sísmico de uma Construção Histórica do Patrimônio Sobralense. Monografia. Universidade Estadual Vale do Acarau -UVA, Sobral, 2017.

FRAZÃO, Maria Tereza de Brito Rações Franco. Modelação de um edifício “Gaioleiro" para Avaliação e Reforço Sísmico. Dissertação de Mestrado. Instituto Superior Técnico de Lisboa, Portugal, 2013.

INTERNATIONAL SCIENTIFIC COMMITTEE FOR ANALYSIS AND RESTORATION OF STRUCTURES OF ARCHITECTURAL HERITAGE. Recommendations for the analysis, conservation and structural restoration of architectural heritage. D.M. del 22/05/2003.

MESQUITA, E. F. T. (2017). Structural characterization and monitoring of heritage constructions. Tese de Doutoramento. Universidade do Porto, Portugal.

MINISTERO DELLE INFRASTRUTTURE E DEI TRASPORTI. Norme Tecniche per le Costruzioni (NTC 2018). D.M. del 14/01/2008. Roma, 2018.

MONTEIRO, R. F. (2012). Um Monumento ao Sertão: ciência, política e trabalho na construção do Açude Cedro. Dissertação de Mestrado. Universidade do Federal do Ceará, Fortaleza.

NEVES, S. M. L. C. Análise Sísmica de um Edifício da Baixa Pombalina. 2008. 123 f. Dissertação (Mestrado em Engenharia Civil) -Instituto Superior Técnico, Lisboa, 2008.

NUNES, Ricardo Filipe Gomes. Modelação e análise de estruturas de edifícios existentes em alvenaria. 2013. Tese de Doutorado. Instituto Politécnico de Tomar. Disponível em: <https:// https://comum.rcaap.pt/handle/10400.26/5822> Acesso em: 8 jan. 2020.

SANTOS, F.; ALVES, A.; BRANDÃO, F.; MESQUITA, E.; DIÓGENES, A.; VARUM, H. (2016). Análise estrutural de uma edificação histórica do Século XVIII. CBPAT 2016, Belém, Brasil; 2016. 